\title{
Railway Freight Safety Comprehensive Detection and Tracking Method Based on IOT
}

\author{
Huawei Wang ${ }^{1, a)}$, Tianyun Shi ${ }^{2, b)}$ and Hui Jiang ${ }^{2, c)}$ \\ ${ }^{1}$ China Academy of Railway Sciences, Beijing 100081, China. \\ ${ }^{2}$ Institute of Computing Technology, China Academy of Railway Sciences, Beijing 100081, China. \\ a)ff0112@163.com, ${ }^{\text {b) }}$ tyshi@rails.cn, ${ }^{c}$ jianghui@ rails.cn
}

Keywords: Railway, Freight safety, Tracking method, IOT.

\begin{abstract}
Considering the present situation of railway freight transportation safety management, this paper puts forward the comprehensive detection and tracking method of railway freight transportation safety. Firstly, the IOT technology is used to realize the comprehensive detection of railway freight transportation safety, and the integrated architecture of IOT system and information integration scheme are studied. Secondly, the freight loading status tracking method is illuminated, the method constructs freight loading status model, the loading status information is also matched based on the membership function. The method can help to complete the whole freight transportation information tracking. The application results show that the comprehensive detection and tracking method is of great value to the safety of railway freight transportation.
\end{abstract}

\section{INTRODUCTION}

The railways are mixed running of freight trains and passenger trains in China. With the implementation of high speed and heavy load strategy, railway freight safety is facing severe challenges. In order to realize the goal of "Ensuring safety by technology, and ensuring transportation order by freight safety ", China Railway Corporation has organized to install a series of freight safety detection equipment and professional application system. However, due to the relevant information belonging to different subsystems, it is hard to complete information integration and application during the whole transportation process, which includes most of all freight activities form origin station, to intermediate station , and to terminal station. So, it is also difficult to achieve the whole railway freight process tracking and monitoring.

The Internet of things (IOT) is one important part of the new generation of information technology which utilizes a variety of intelligent sensing technologies and devices to percept the physical world. IOT can achieve the goal of information exchange and seamless connection between people and things through the network interconnection, computing, processing and knowledge mining. Since the technology of IOT was put forward, it has attracted the attention of governments and scientific research institutions, and the application of IOT has been carried out in various industries. The IOT technology has played an important role in promoting the development of intelligent railway in our country. Many scholars have carried out the research on the application of IOT in the railway industry. Xiaoning Ma [1] has analyzed the typical IOT application form in China railway field. Peng Sun [2] has proposed EMU maintenance design method on IOT, and has illustrated the overall architecture and key technologies. In addition, Zeyan Zhou [3] designed a set of railway ticket system based on the IOT three layer architecture, which can effectively improve the system processing quality and increase passenger transport efficiency.

By analyzing the current situation of railway freight safety monitoring and business requirements, the paper carries out the research on railway freight safety comprehensive detection IOT architecture, and put forward the whole freight process loading status tracking scheme, which can implement the freight safety detection and tracking from the origin station to the terminal station. The research will help to improve the ability of freight transportation security and realize the long term stability of freight management. 


\section{RAILWAY FREIGHT SAFETY COMPREHENSIVE DETECTION BASED ON IOT}

\section{IOT Concept and Architecture Model}

The IOT technology is a kind of extended network technology based on internet. It can connects things and internet to do information exchange and communication according to agreed protocol by RFID, infrared sensors, global positioning systems and laser scanners. This network technology can be used to achieve intelligent recognition, positioning, tracking, monitoring and management [4]. The initial stage of IOT is to recognize and obtain the fundamental information of the things automatically, the advanced stage of IOT is to implement the intelligent control of the things.

The system architecture model of IOT is generally divided into 3 layers: perception layer, network layer and application layer. As shown in figure 1, perception layer is the foundation of IOT architecture, which mainly utilizes RFID, sensing technology, controlling technology and GPRS. Network layer is the foundation of data transmission, it can realize the information transmission and exchange on private network, telecommunication network, internet and other communication networks [5]. Application layer, which is combined IOT technology with specific technology, can achieve the interface between network layer and application service, this layer also completes analyzing data of perception, information sharing and processing intelligently. Besides, it will provide the common or custom application services [6].

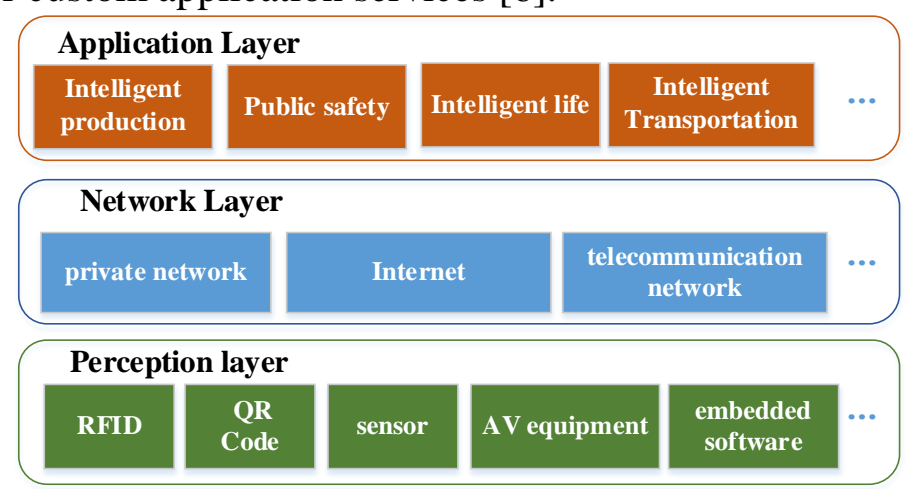

FIGURE 1. Architecture of Internet of things.

\section{The Architecture of Railway Freight Safety Comprehensive Detection IOT}

In order to ensure the quality of railway transportation, and establish a long-term safety mechanism, China Railway Corporation has put forward the idea of establishing freight safety guarantee system, and accelerated the construction and application of railway freight safety detection equipment and systems. The main equipment includes unbalanced loading detecting devices, weight bridges, threshold detection devices, video devices, handheld devices and so on. Among of these, weight bridges, video devices for loading, handheld devices for loading are mainly used in origin station and terminal station; Unbalanced loading detecting devices, threshold detection devices, handheld devices for security inspection are mainly used in the railway freight inspection station (i.e. freight intermediate station). All of the equipment can recognize and obtain the information of the freight loading status automatically. These detection equipment has greatly promoted the construction of the railway freight safety IOT, and will help to complement railway freight loading status detection and monitoring of. [7]

Considering the business requirements of railway freight loading status management, the architecture of the railway freight safety IOT is put forward according to the above architecture concept model. 


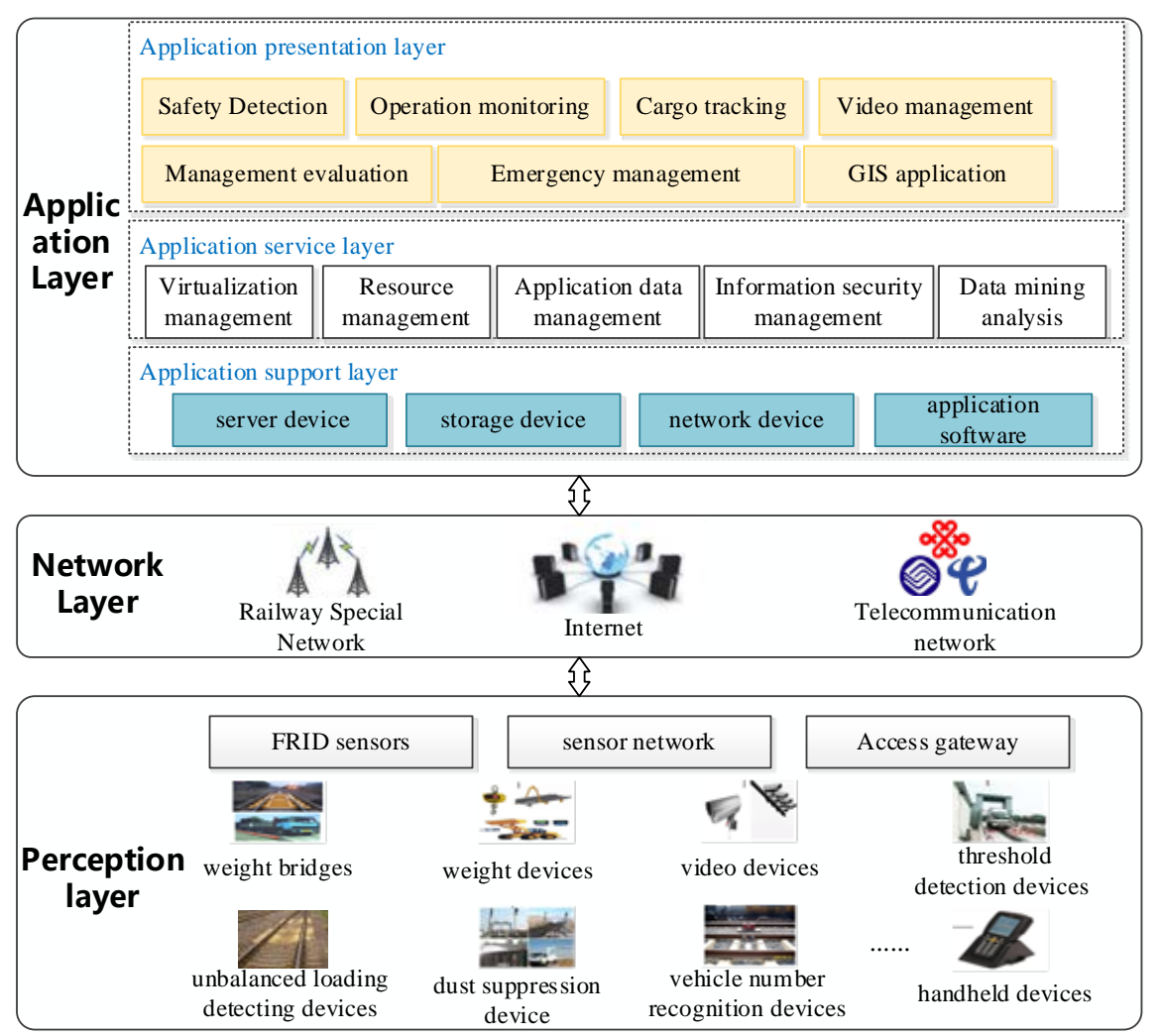

FIGURE 2. The Architecture of Railway Freight Safety Comprehensive Detection IOT

(1) Perception layer: mainly includes all kinds of freight safety inspection devices with FRID labels or sensor, sensor networks and the access gateway. Which are respectively responsible for information collection of the freight security and job, short distance wireless communication and networking, the heterogeneous network access, and the management of the terminal equipment.

(2) Network layer: mainly includes various core hosted network, access network, etc. Such as wired Internet, wireless mobile communication network (2G, 3G, and 4G) and the private railway network. They are responsible for the railway freight safety IOT long-distance information transmission and short distance network access.

(3) Application layer: can be divided into application support layer, application service layer, application presentation layer. Application support layer mainly provide the necessary software and hardware support which the physical network need. The support includes all kinds of server device, storage device, network device and related software. Application service layer is responsible for providing application support according to requirements, such as virtualization management, resource management, data management (e.g., fuzzy recognition, intelligent control, search engine, etc.), information security management and data mining analysis and so on. Application presentation layer mainly include all kinds of application subsystems, portals. The layer is responsible for providing all kinds of railway freight application services based on IOT [8, 9]. These services can help to complete railway freight internal management and external information sharing.

\section{Railway Freight Safety Comprehensive Detection Information Integration}

The main information sources of railway freight safety comprehensive detection IOT are freight safety monitoring and management subsystems, which can provide the freight transportation operation information, security detection and alarm information, alarm disposal and feedback information. The freight safety comprehensive detection IOT will meet the needs of the whole freight process monitoring through the effective integration of railway freight safety inspection information [10, 11].

Railway freight safety integrated detection IOT platform uses two kinds of information integration-database information integration and application system information integration as 
figure 3 showed. Database information integration, is used for freight internal information, such as freight operation and safety information, which exchanges frequently and contacts business closely. Application system information integration, is used for the railway transport integration platform, railway freight e-commerce platform etc., because the information from these systems are relatively independent.

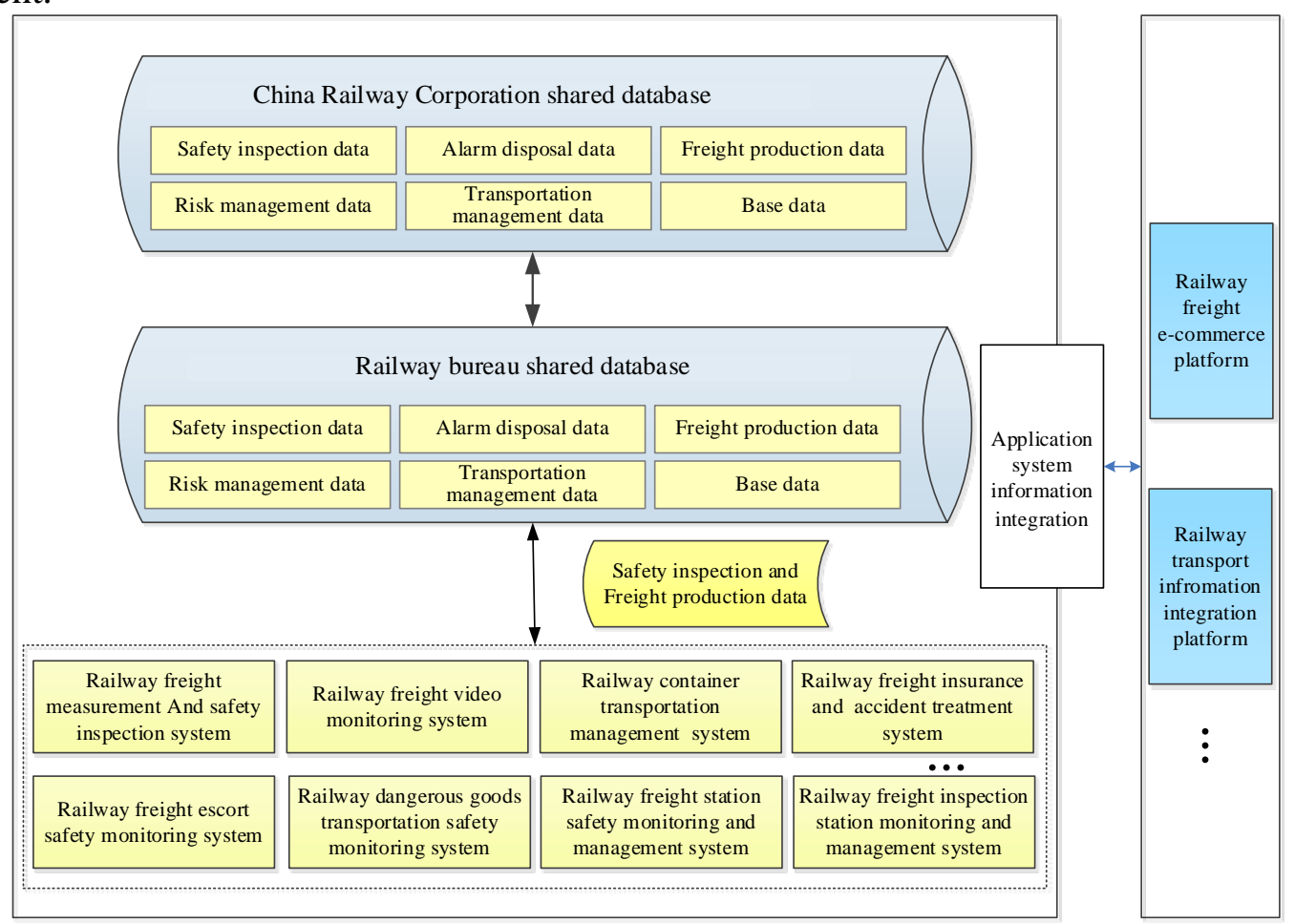

FIGURE 3. Railway freight safety comprehensive detection IOT integration schematic diagram

\section{FREIGHT LOADING STATUS TRACKING METHOD}

\section{Freight Loading Status Tracking Data Analysis}

In fact, the freight loading status tracking of the whole process is collecting and querying loading status information. Therefore, the information collecting during transporting is the foundation to achieve freight loading status tracking. Freight loading status information can be divided into static information and dynamic information according to changing frequency. Static information is generally stable information in the process of transportation, such as the weight of the goods, goods name, origin station, origin railway bureau, terminal station, and terminal railway bureau and so on. Dynamic information is the changing information in the process of transportation, such as freight loading status detection information, location information, operation information etc.

In order to realize the railway freight loading status tracking of the whole process, all the information need to be effectively integrated from loading to unloading. The mainly related data is analyzed as shown in table 1: 
TABLE 1. Freight Loading Status Tracking Data Analysis Table.

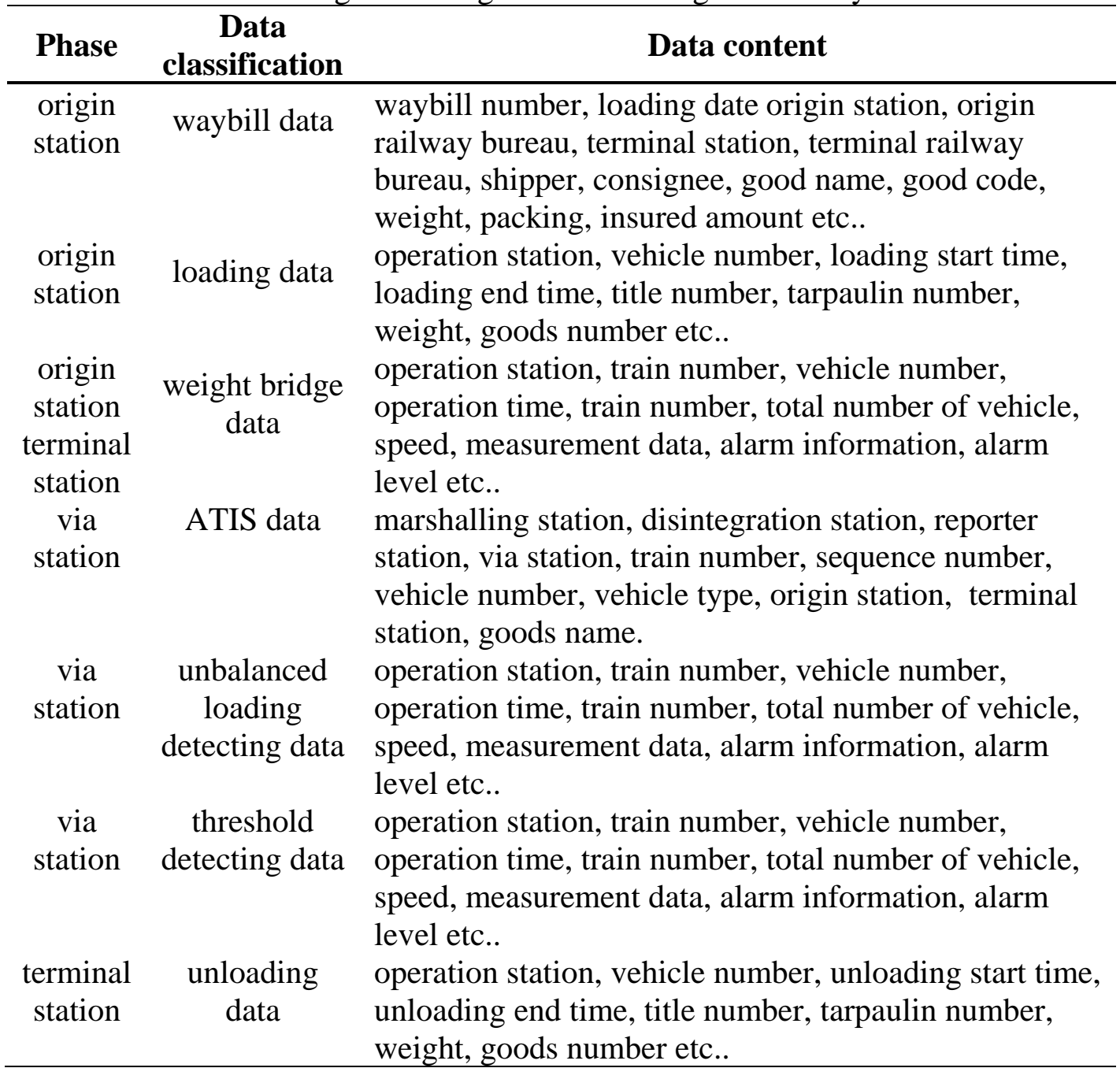

\section{Definition of Freight Loading Status Model}

Because freight loading detection, operation and other activities of the freight process is discrete, there is a time interval between each activity, the freight loading status tracking is a discrete, discontinuous point tracking. If the full freight loading status tracking sequence is denoted with $S$, at a certain time, the freight loading status is denoted with $S_{i}$, then:

$$
\begin{gathered}
S=\left\{S_{1}, S_{2}, S_{3}, \cdots, S_{n}\right\} \\
S_{i}=\left\{P_{i 1}, P_{i 2}, P_{i 3}, \cdots, P_{i m}\right\}
\end{gathered}
$$

In formula (2), $\mathrm{P}_{i 1}, \mathrm{P}_{i 2}, \mathrm{P}_{i 3}, \cdots, \mathrm{P}_{i m}$ indicate the various parameters of the railway freight loading status at some point. The freight loading status is changed with a series of activities in the process of transportation, and each new loading status $S_{i+1}$ is generated from the previous loading status $S_{i}$ under the action of activity $A_{i}$, we can obtain

$$
S_{i+1}=A_{i}\left(S_{i}\right)
$$

The whole process of freight loading status tracking is the process of collecting and updating the information in the course of transportation. The process can be expressed by

$$
S_{0} \rightarrow\left(S_{0}, S_{1}\right) \rightarrow\left(S_{0}, S_{1}, S_{2}\right) \rightarrow \cdots \rightarrow\left(S_{0}, S_{1}, S_{2}, \cdots, S_{n}\right)
$$

Therefore, the final result of the whole process of railway freight loading status tracking is $\left(S_{0}, S_{1}, S_{2}, \cdots, S_{n}\right)$. 


\section{Freight Loading Status Tracking Based On Membership Function}

Freight loading status tracking relies not only on the vehicle number, but also on goods loading information, transportation time etc. The information above mentioned belongs to different freight subsystems, the waybill number information which can denote the whole transportation process only is reflected in the loading information. Therefore, we need to correctly match the loading status information with waybill number, and realize the scattered freight loading status information fusion. It will be the key to the realize freight safety comprehensive monitoring and tracking of the whole transportation process.

\section{(1) Membership function theory}

The membership function is used to describe the fuzziness object quantitatively. Set $U$ as the domain (the scope of the research), any element $\mathrm{x}$ in $U$, there is a corresponding number $A(\mathrm{x}) \in[0,1]$, then $A$ is called the fuzzy set on $U$, known as the membership degree of $\mathrm{x}$ versus $A$. When $\mathrm{x}$ changes in $U, A(\mathrm{x})$ is a function, which is called the membership function of $A$ [12].

\section{(2) Whole process tracking model based on membership function}

In order to realize the loading status related information integration with the waybill number, and to establish the correct matching relation, the main steps of the whole process tracking model can be concluded as follows.

Step 1: Set $U$ as the collected freight related loading status information, A denote a set of freight loading status information, which is identified by the waybill number. Any element in $U$ is railway freight loading status at any time, corresponding to $S_{i}$ in the formula (2). $A\left(S_{i}\right)$ expresses the degree of membership $S_{i}$ versus $A$. The degree of membership $A\left(S_{i}\right)$ is closer to 1 , the higher $S_{i}$ belongs to $A$, the degree of membership $A\left(S_{i}\right)$ is closer to 0 , the lower $S_{i}$ belongs to $A$ [13].

Step2: According to the expert experience, We analyze the parameters $\mathrm{P}_{i 1}, \mathrm{P}_{i 2}, \mathrm{P}_{i 3}, \cdots, \mathrm{P}_{i m}$ in formula(2) which have important impact on the degree of membership , including waybill number, vehicle number, origin station, terminal station, goods name, passing time, the detection station and so on. We also clarify the weight of each parameter to match with waybill number, and then determine the loading status membership function.

Step 3: Based on the membership function, we calculate the probability value of $S_{i}$ to $A$, so as to deduce whether $S_{i}$ and bill number of $A$ match or not, which is the same as loading status information integration with waybill number.

Step 4: According to a certain search criteria, we can finish searching related freight loading status during the whole freight trip.

\section{APPLICATION AND IMPLEMENTATION}

Based on the freight safety comprehensive detection and tracking method, a prototype system of railway freight safety comprehensive monitoring and tracking IOT system is built. The system has been applied in some railway bureaus. In the third quarter of 2016, some railway bureaus' freight safety detection and alarm evaluation results are shown in table 2.

TABLE 2. Freight Safety Detection and Alarm Evaluation Results.

\begin{tabular}{cccc}
\hline $\begin{array}{c}\text { Railway } \\
\text { Bureau }\end{array}$ & $\begin{array}{c}\text { Vehicle } \\
\text { Number }\end{array}$ & $\begin{array}{c}\text { Detection } \\
\text { Number }\end{array}$ & $\begin{array}{c}\text { Alarm } \\
\text { Number }\end{array}$ \\
\hline HE & 791150 & 67 & 56 \\
SY & 1191903 & 137 & 117 \\
BJ & 960245 & 60 & 59 \\
TY & 1979351 & 13 & 13 \\
HH & 491546 & 32 & 27 \\
ZZ & 567885 & 12 & 12 \\
SH & 1219719 & 50 & 50 \\
\hline
\end{tabular}


We have selected the freight loading information of Shanghai Railway bureau in the third quarter of 2016, so that we can carry out information mapping and tracking based on membership function. There are 173,404 pieces of effective loading information, 153,868 pieces of unloading information, and 1,920,848 pieces of relevant loading status information are integrated successfully, the information matching rate is $90.5 \%$. So we have mostly achieved the goal of freight loading status tracking. The tracking result is shown in table 3.

TABLE 3. Freight Loading Status Tracking Results.

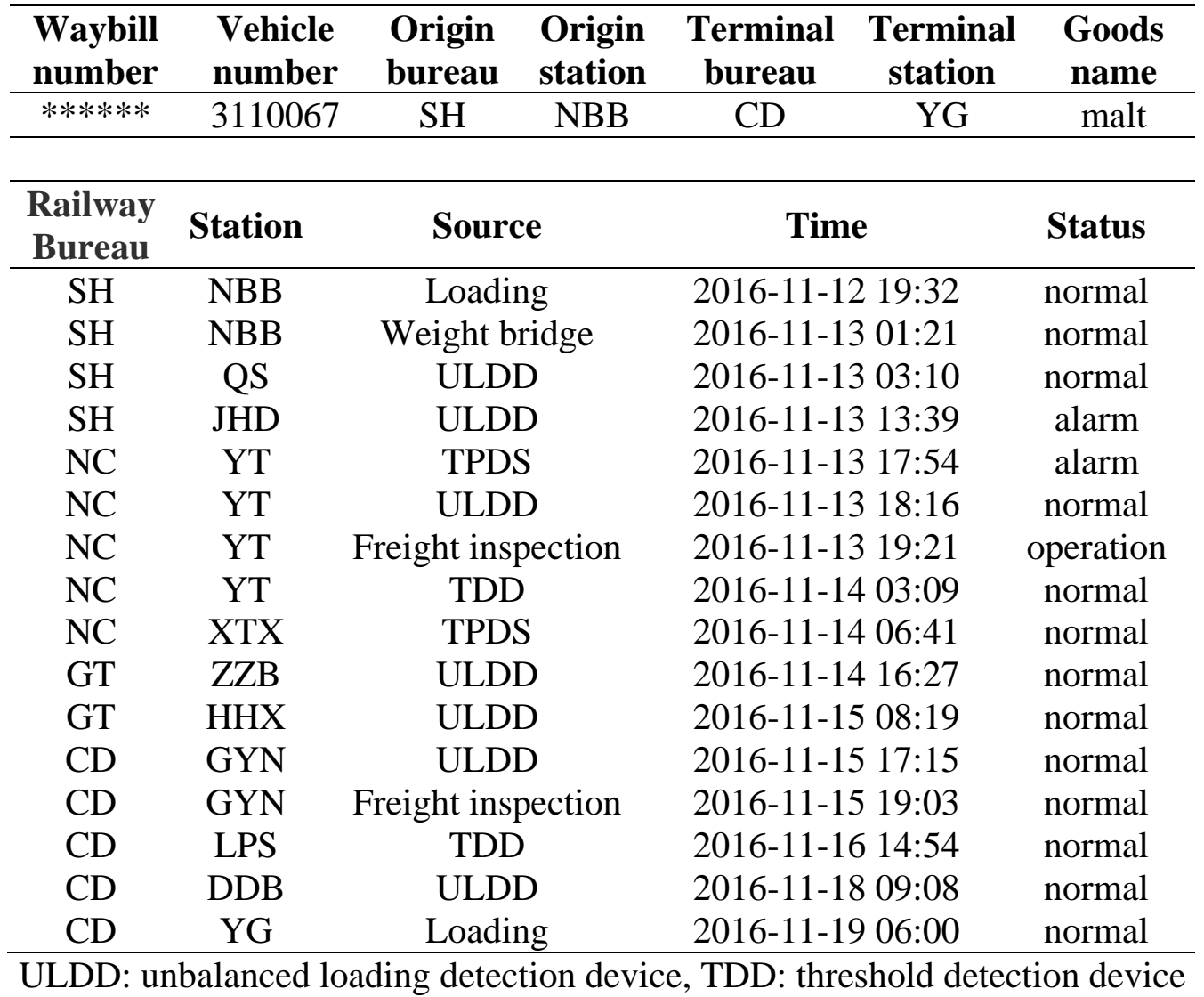

\section{CONCLUSION}

This paper has brought up the architecture of railway freight safety monitoring of IOT by analyzing the situation of railway freight safety monitoring business requirements, and studied the method of freight loading status tracking based on membership function, so that the safety monitoring and tracking through the whole process of freight can be achieved. The research play an important role in ensuring the railway freight security.

\section{ACKNOWLEDGMENTS}

This work was financially supported by research and development plan project in China Railway Corporation: Research on Railway Freight Safety and Emergency Rescue Integrated Platform (2014X012-A).

\section{REFERENCES}

[1].Ma Xiaoning, Ma Xiaojun, Shi Tianyun, Li Ping, Research on Application of Internet of Things Technology in Railway, China Railway, 2015, no. 7, pp. 40-44.

[2].Sun Peng, Research on the Key Technologies of Maintenance Network of the EMUs, China Academy of Railway Sciences, Beijing, 2013. 
[3].Zhou Zeyan, Discussion on Railway Passenger Ticket System Based on Internet of Things and Its Security Strategy, Railway Computer Application, 2015, vol. 24, no. 2, pp. 79-82.

[4].Huang Guitian, Gong Liutang, Zhang Quansheng, Annual report on China’s internet of things development, Social Sciences Academic, Beijing, 2011, pp. 1-98.

[5].Wang Ruchuan, Sun Lijuan, An introduction to the internet of things technology, Tsinghua University Press, Beijing, 2011, pp. 10-150.

[6].Sa Wenqi, Zhang Sherong, Zhang Lianming, Real-time safety evaluation and early warning of large-scale underground cavern group during construction period based on internet of things, Journal of Rock Mechanics and Geotechnical Engineering, 2014, vol. 33, no. 11, pp.2301-2013.

[7]. China Railway Academy of Sciences, Railway Freight Safety Monitoring and Management System Report, Beijing, 2014.

[8].Chui M C, Loffer M, Roger R., The Internet of things, Mckinsey Quarterly, 2010, vol. 2, pp.1-9.

[9].Liu Y H, Introduction to IOT, Science Press, Beijing, 2010, pp. 8-28.

[10]. Huawei Wang, Hui Jiang, Jin Zhu, Railway Freight Escort Safety Monitoring System based on IC card, Railway Computer Application, 2016, vol. 25, no. 4, pp. 10-18.

[11]. Hui Jiang, Liu Chun-huang, Huawei Wang, Research on Dynamic Inspection and Monitoring Key Technologies of Railway Freight Loading Status, International conference on computational intelligence and software engineering, 2012, pp.76-82.

[12]. Chen Shuili, Li Jinggong, et al., Fuzzy Set Theory and Its Application, Science Press, Beijing, 2005.

[13]. Zhao Yugang, Ju Jianbo, Zhang Jingwei, Research on Electronic Equipment Fault Prediction Based on Membership Function Computer Measurement and Control, Computer Measurement and Control,2015, vol. 23, no. 7, pp. 2305-2307. 